\title{
The emergency department approach to violently injured patient care: a regional survey
}

\author{
D L Wilkinson, E M Kurtz, P Lane, * J A Fein
}

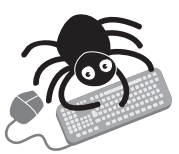

The appendix to this article can be viewed on our website.

See end of article for authors' affiliations

Correspondence to:

Dr D L Wilkinson,

Department of Criminal

Justice, Temple University

1115 W Berks Street (025

02), Philadelphia, PA

19122, USA:

deanna.wilkinson@

temple.edu

Accepted 27 March 2005

.

Objective: Since the early 1990s public health workers have challenged healthcare practitioners to take an active role in violence prevention with patients aged 10-24 years. Emergency department (ED) clinicians are uniquely positioned to identify, assess, and refer youth involved in violent events. The objective of this study was to describe ED directors' estimate of the number of violently injured youth seen, the presence of established protocols or guidelines for handling youth violence, and the type of training programs offered to ED physicians regarding this issue.

Methods: The authors conducted a survey of EDs $(n=64)$ in the Philadelphia metropolitan region to determine the standard of ED care for violently injured youths. Half of the EDs were in urban areas and half in suburban.

Results: A total of 41 out of 64 (64.1\%) ED directors completed and returned the written questionnaire. In addition to treating the specific injuries sustained, ED responses to youth violence primarily involved talking with patients about the events surrounding the injury. The estimated number of violently injured youth seen per month varied considerably. Twenty four directors $(58.5 \%)$ estimated that their institution treated fewer than 10 per month; 10 (24.4\%) reported 11-30, and seven (17.1\%) mostly large urban hospitals, saw more than 30 per month. Although most hospitals reported that the staff counsels patients about safety concerns, only 17\% offered their staff formal training programs on youth violence.

Conclusions: To address the prevention of youth violence, EDs need specific training programs for ED staff, as well as systematic risk assessment and referral resources for structured intervention and follow up.

$\mathrm{P}$

rompted by alarming rises in youth violence rates in the United States, medical professionals have been viewing youth violence as a public health issue since the early 1990s. Prothrow-Stith suggested that emergency department (ED) workers should conduct risk assessments, counseling, and referrals to community support services for these youth. ${ }^{1}$ In 1996 a panel of the American Academy of Pediatrics developed a model protocol for dealing with adolescent assault victims. The panel recommended that ED practitioners develop treatment plans to reduce the likelihood of re-injury and to deal with stress reactions. ${ }^{2}$ Similarly, in 1999, the American Academy of Pediatrics Task Force on Violence called for "preventive education, screening for risk, and linkages to necessary intervention and follow-up services". ${ }^{3}$ Other public health and medical experts have published similar calls to action. ${ }^{4-6}$

Health based violence prevention programs are often based in schools or in the primary care office. ${ }^{7-10}$ Urban adolescents, who are at highest risk for severe violent injury, often seek acute medical care in the ED rather than at primary care sites. ${ }^{11}{ }^{12}$ There is some evidence that hospital based violence prevention programs can be implemented to influence future risk factors for re-injury. ${ }^{13}{ }^{14}$ Although ED based interventions have not demonstrated equal efficacy, studies indicates that clinicians are able to assess important psychosocial needs and link injured youth with social service agencies. ${ }^{15-17}$ However, it is not clear if ED personnel have begun to incorporate violence prevention efforts into their routine practice. The objective of this study was to describe ED directors' estimate of the number of violently injured youth seen, the presence of established protocols or guidelines for handling youth violence, and the type of training programs offered to ED physicians regarding this issue.

\section{METHODS}

The present study examines ED based approaches to patients injured as a result of community youth violence, excluding child abuse. A written, self-administered questionnaire was

Abbreviations: ED, emergency department. 
Table 1 Patient volume of urban and suburban hospitals $(n=41)$

\begin{tabular}{lccc}
\hline $\begin{array}{l}\text { Estimated patient volume } \\
\text { per month }\end{array}$ & $\begin{array}{l}\text { Urban* } \\
\text { hospitals } \\
\text { (n, \%) }\end{array}$ & $\begin{array}{l}\text { Suburbant } \\
\text { hospitals } \\
\text { (n, \%) }\end{array}$ & Total (n, \%) \\
\hline None & $0(0 \%)$ & $1(6.7 \%)$ & $1(2.4 \%)$ \\
$1-5$ & $7(26.9 \%)$ & $10(66.7 \%)$ & $17(41.5 \%)$ \\
$6-10$ & $5(19.2 \%)$ & $1(6.7 \%)$ & $6(14.6 \%)$ \\
$11-20$ & $4(15.4 \%)$ & $0(0 \%)$ & $4(9.8 \%)$ \\
$21-30$ & $4(15.4 \%)$ & $2(13.3 \%)$ & $6(14.6 \%)$ \\
More than 30 & $6(23.1 \%)$ & $1(6.7 \%)$ & $7(17.1 \%)$ \\
Total & 26 & 15 & 41 \\
\hline
\end{tabular}

*Urban counties include Philadelphia and Camden.

†Suburban counties include Bucks, Burlington, Chester, Delaware Montgomery, and Gloucester.

sent to the directors of 64 EDs in the Philadelphia metropolitan area, one half (32) of which were urban and the other half suburban. Research assistants made up to three telephone calls to obtain responses. The questionnaire was adapted from a previously used measure, ${ }^{18}$ and included 10 forced choice and open ended questions. (see appendix A) We used SPSS (version 11.0, SPSS Inc, Chicago, IL, USA) for the data analysis. This study was approved by the University's institutional review board.

\section{RESULTS}

A total of 41 out of $64(64.1 \%)$ complete questionnaires were returned-81.3\% for urban programs and $46.9 \%$ for suburban programs. The estimated number of violently injured youth seen per month varied considerably. Twenty four directors $(58.5 \%)$ estimated that their institution treated fewer than 10 per month; $10(24.4 \%)$ reported $11-30$, and seven $(17.1 \%)$ mostly large urban hospitals, saw more than 30 per month. (table 1)

\section{Identification and event details}

Almost all reported that ED personnel routinely determine the context of the event that caused the injury, and more than three quarters report that the staff regularly asked who caused the patient's injury (table 2).

\section{Assessment for safety and risk}

Most ED directors also reported that their staff members assess the risk for further injury (table 2). Most stated that clinicians talk with the patient about safety concerns while in the ED; just over one quarter reported that ED personnel determine the likelihood of a repeat attack, and one fifth reported that they determine whether or not the patient had plans to retaliate.

\section{Intervention and referral}

Most directors acknowledged that their staff members do not routinely intervene on behalf of a violently injured patient. About one third routinely referred injured patients to either a social worker or chaplain or counselled the patient themselves about possible ways to increase their safety. One quarter routinely provided information about community based violence prevention programs. Mandatory reporting of penetrating wounds is required in Philadelphia but there is no systematic monitoring of compliance with this requirement. Only two hospitals routinely contacted the police or suggested that the victim do so.

We asked ED directors to specify which health professionals should ask patients about the events that led to their violent injuries (table 3); most felt that physicians or nurses should ask about the event. However, slightly more than half felt that this was an appropriate task for physician's
Table 2 Care routines with violently injured youth $(n=41)$

\begin{tabular}{lc}
\hline Routine & $\begin{array}{l}\text { Number of } \\
\text { respondents (n, \%) }\end{array}$ \\
\hline $\begin{array}{l}\text { Identifying/gathering data } \\
\text { Determine context of the event that caused } \\
\text { injury }\end{array}$ & $38(92.7 \%)$ \\
$\begin{array}{l}\text { Determine who caused injury } \\
\text { Determine if there were witnesses to the } \\
\text { injury event }\end{array}$ & $32(78.0 \%)$ \\
Assessing patient safety and risks & $11(26.8 \%)$ \\
$\begin{array}{l}\text { Talk with patient about safety concerns } \\
\text { Determine likelihood of a repeat attack }\end{array}$ & $29(70.7 \%)$ \\
$\begin{array}{l}\text { Determine if patient plans to retaliate } \\
\text { Referring/counselling patient }\end{array}$ & $8(29.3 \%)$ \\
$\begin{array}{l}\text { Talk with patient about safety concerns } \\
\text { Refer patient to social worker or chaplain }\end{array}$ & $29(70.7 \%)$ \\
$\begin{array}{l}\text { Counsel patients about ways to increase } \\
\text { safety }\end{array}$ & $14(39.0 \%)$ \\
$\begin{array}{l}\text { Speak with family/friends about increasing } \\
\text { safety }\end{array}$ & $12(29.3 \%)$ \\
$\begin{array}{l}\text { Provide numbers of violence prevention } \\
\text { programs }\end{array}$ & $10(24.4 \%)$ \\
$\begin{array}{l}\text { Contact violence prevention program for } \\
\text { patient }\end{array}$ & $3(7.3 \%)$ \\
Contact police & $2(4.9 \%)$ \\
\hline
\end{tabular}

Table 3 Talking with violently injured patients: which health professionals should? $(n=41)$

\begin{tabular}{lc}
\hline Health professional & Number of respondents (n, \%) \\
\hline Physicians & $41(100 \%)$ \\
Nurses & $39(95.1 \%)$ \\
Physician's assistants & $22(53.7 \%)$ \\
Nurse practitioners & $23(56.1 \%)$ \\
Social workers & $23(56.1 \%)$ \\
Psychologists & $10(24.4 \%)$ \\
Chaplain & $9(22 \%)$ \\
\hline
\end{tabular}

assistants, nurse practitioners, and/or social workers. Only $20 \%$ thought chaplains or psychologists would be appropriate

Only seven $(17.1 \%)$ respondents stated that their ED had a formal violence prevention program. Most of the others stated that their hospital had never considered having such a program although many indicated that they would be interested in collaborating with existing programs.

\section{DISCUSSION}

The ED is often the only source of health care for youth most likely to sustain intentional injuries. ${ }^{12}$ Psychosocial assessment of violently injured youth has been endorsed by several professional organizations. ${ }^{19}$ The incidence of intentionally inflicted (non-child abuse) injuries cared for in the EDs studied varied considerably. This is not surprising given the geographic concentration of violence perpetration in urban Philadelphia. ${ }^{20} 21$

In general, ED directors do not believe it is likely that patients are referred to specialized hospital staff or programs to prevent further violent injury. The lack of existing violence prevention and staff training programs is especially vexing for hospitals with more than 20 incidents per month because, although they may benefit the most from such a program, they may also be the busier EDs and therefore have less time to devote to such an endeavor.

Similar results have been reported by Fein and colleagues. ${ }^{18}$ Our study did not find the high rate of referrals to social workers or clergy reported in the Fein study. This may reflect 


\section{Key points}

- Emergency department (ED) directors recognize the need for ED clinicians to perform some psychosocial assessment of young violently injured patients.

- Although most ED practitioners will address a violently injured patient's overt safety concerns, few ask directly about retaliation or the likelihood of repeat attack.

- When faced with social or safety concerns, ED practitioners are more likely to address them directly than to access resources outside of the immediate medical surroundings.

- Formalized youth violence prevention and training programs for ED staff are rare.

- Additional research on ED based youth violence programs is needed.

the fact that most of the clinicians surveyed in the earlier study worked in a tertiary care children's hospital where there was full time social work coverage.

\section{Limitations}

The data collected were from the fifth largest city in the United States and one that has a relatively high violent crime rate. ${ }^{22}$ Neither the validity nor reliability of the survey instrument was tested, although many of the questions were used in an earlier study ${ }^{18}$ Because the majority of the 23 nonresponders were suburban hospitals, the data are likely to underrepresent hospitals with lower volumes of intentional youth violence. It is possible that non-responding suburban ED directors did not consider this issue important enough to warrant a response.

We excluded child abuse and domestic violence from this study because many of the issues related to the care of these patients are distinct from those of youth violence. Finally, our data are based on the perceptions of ED directors and we do not know how accurately these perceptions reflect actual practices. Fein's study demonstrated that clinicians have misconceptions about youth violence protocols within their home institution, with $85 \%$ of respondents believing that the hospital had a formal protocol when in fact they did not. ${ }^{18}$

This study demonstrates that ED directors support the promotion of clinician education around the management of violently injured youth, and most expressed an interest in collaborating with violence prevention programs at other institutions. However, it is important to recognize that the behaviors of ED clinicians may not change unless ED based violence prevention programs demonstrate some benefit to their patients and to society. An evaluation of the ED based Boston Violence Prevention Project, which provided initial ED assessment and subsequent community based follow up, found no detectable differences between the treatment and control groups. ${ }^{14}$ There is a clear need for empirical evidence of the efficacy of ED based safety screening and psychosocial assessment of the violently injured youth.

\section{Authors' affiliations}

D L Wilkinson, E M Kurtz, Department of Criminal Justice, Temple University, Philadelphia, PA, USA

P Lane*, Departments of Emergency Medicine, Albert Einstein Medical Center and Thomas Jefferson University Medical College

J A Fein, Departments of Pediatrics and Emergency Medicine, The University of Pennsylvania School of Medicine and The Children's Hospital of Philadelphia, Philadelphia, PA, USA

*Dr Lane died before this work was published.

The authors gratefully acknowledge funding support from the William Penn Foundation and data collection assistance from Kristan Ware and Brannon Ottley.

The authors have no competing interests to declare related to this publication.

\section{REFERENCES}

1 Prothrow-Stith D. Can physicians help curb adolescent violence? Hosp Pract 1992;27:193-207

2 American Academy of Pediatrics. Task force on adolescent assault victims needs a review of issues and a model protocol. Pediatrics 1996;98:991-1001.

3 American Academy of Pediatrics Taskforce on Violence. The role of the pediatrician in youth violence prevention in clinical practice and at the community level. Pediatrics 1999;103:173-81.

4 Anglin T. The medical clinician's roles in preventing adolescent involvement in violence. Adolesc Med 1997;9:501-15

5 Christoffel K, Spivak H, Witner M. Youth violence prevention: the physician's role. JAMA 2000;283:1202-3.

6 Shepherd J, Sivarajasingam V, Rivara FP. Using injury data for violence prevention. BMJ 2000;321:1481-2.

7 Hausman A, Prothrow-Stith D, Spivak H. Implementation of violence prevention education in clinical settings. Patient Educ Couns 1995;25:205-10.

8 Hausman A, Spivak H, Prothrow-Stith D, et al. Patterns of teen exposure to a community-based violence prevention project. J Adolesc Health 1992:13:668-75

9 Johnson C, Fein JA, Campbell C, et al. Violence prevention in the primary care setting: a program for pediatric residents. Arch Pediatr Adolesc Med 1999; 153:531-5

10 Barkin S, Ryan G, Gelberg L. What pediatricians can do to further youth violence prevention. Inj Prev 1999;5:53-8.

11 Wilson KM, Klein JD. Adolescents who use the emergency department as their usual source of care. Arch Pediatr Adolesc Med 2000;154:361-5.

12 Ziv A, Boulet J, Slap G. Emergency department utilization by adolescents in the United States. Pediatrics 1998;101:987-94.

13 Becker MG, Hall JS, Ursic CM, et al. Caught in the Crossfire: the effects of a peer-based intervention program for violently injured youth. J Adolesc Health 2004;34:177-83.

14 De Vos E, Stone D, Goetz M, et al. Evaluation of a hospital-based youth violence intervention. Am J Prev Med 1996;12:101-8.

15 Zun LS, Downey LV, Rosen J. An emergency department-based program to change attitudes of youth toward violence. J Emerg Medicine 2004;26:247-51.

16 Zun LS, Downey LV, Rosen J. Violence prevention in the ED: linkage of the ED to a social service agency. Am J Emerg Med 2003;21:454-7.

17 Zun LS, Rosen JM. Psychosocial needs of young persons who are victims of interpersonal violence. Pediatr Emerg Care 2003;19:15-19.

18 Fein J, Ginsburg KR, McGrath ME, et al. Violence prevention in the emergency department: clinician attitudes and limitations. Arch Pediatr Adolesc Med 2000;154:495-8.

19 Horowitz L, Kassam-Adams N, Bergstein M. Mental health aspects of emergency medical services for children: summary of a consensus conference. Acad Emerg Med 2001;8:1 187-96.

20 Fingerhut L, Christoffel KK. Firearm-related death and injury among children and adolescents. Future Child 2002;12:25-37.

21 Tierney J, Loizillon A. Violence reduction. Philadelphia: Public Private Ventures, 1999.

22 Blumstein A, Wallman J, eds. The Crime Drop in America. New York: Cambridge University Press, 2000. 